\title{
A REESTRUTURAÇÃO DA PROFISSÃO DOCENTE NO CONTEXTO DA NOVA GESTÃO PÚBLICA NA AMÉRICA LATINA
}

\author{
Dalila Andrade Oliveira (UFMG)
}

\begin{abstract}
RESUMO
O artigo discute mudanças ocorridas na profissão docente, nas duas últimas décadas no contexto latino-americano, com da introdução da Nova Gestão Pública (NGP). Procura demonstrar como os princípios da NGP vão se impondo na orientação das políticas públicas traduzindo-se em normas, procedimentos administrativos e em práticas que vão transformando valores e identidades junto aos profissionais docentes. Esse discurso penetra o campo da formação docente e das práticas profissionais no sistema educacional, revelando intencionalidades convergentes com os objetivos da reforma em relação aos processos escolares, determinando novas lógicas de organização e gestão que interferem nas relações de trabalho promovendo a reestruturação da profissão docente.
\end{abstract}

Palavras-chave: Profissão docente. Nova gestão pública. Novo profissionalismo.

\section{ABSTRACT \\ THE RESTRUCTURING OF TEACHING PROFESSION IN THE CONTEXT OF NEW PUBLIC MANAGEMENT IN LATIN AMERICA}

The article discusses changes in the teaching profession, in the last two decades in the Latin American context, with the introduction of the New Public Management (NPM). It seeks to demonstrate how the principles of NPM are being imposed in the orientation of public policies, translating into norms, administrative procedures and practices that are transforming values and identities with the teaching professionals. This discourse penetrates the field of teacher education and professional practices in the educational system, revealing intentionalities convergent with the reform objectives in relation to the school processes, determining new logics of organization and management that interfere in the labor relations promoting the restructuring of the teaching profession. Keywords: Teaching profession. New public management. New professionalism.

\section{RESUMEN}

\section{LA REESTRUCTURACIÓN DE LA PROFESIÓN DOCENTE EN EL CONTEXTO DE LA NUEVA GESTIÓN PÚBLICA EN AMÉRICA LATINA}

El artículo discute cambios ocurridos en la profesión docente, en las dos últimas décadas en el contexto latinoamericano, con la introducción de la Nueva Gestión Pública (NGP). Se busca demostrar cómo los principios de la NGP se van imponiendo en la orientación de las políticas públicas traduciéndose en normas, procedimientos

* Doutora em Educação pela Universidade de São Paulo (USP). Professora Titular de Políticas Públicas em Educação (UFMG). Pesquisadora do CNPq. E-mail: dalilaufmg@yahoo.com.br 
administrativos y en prácticas que van transformando valores e identidades junto a los profesionales docentes. Este discurso penetra el campo de la formación docente y de las prácticas profesionales en el sistema educativo, revelando intencionalidades convergentes con los objetivos de la reforma en relación a los procesos escolares, determinando nuevas lógicas de organización y gestión que interfieren en las relaciones de trabajo promoviendo la reestructuración de la profesión docente.

Palabras clave: Profesión docente. Nueva gestión pública. Nuevo profesionalismo.

\section{Introdução'}

Este artigo discute mudanças ocorridas na profissão docente nas duas últimas décadas no contexto latino-americano, com a introdução da Nova Gestão Pública (NGP) em um grande número de países da região. Procura demonstrar como um modelo de regulação se implanta a partir dos anos 1990 nessa região, tendo a NGP como importante instrumento na relação de governação entre os atores do Estado e da sociedade civil. Por meio de um discurso reformador no âmbito do Estado e da educação, os princípios da NGP vão se impondo na orientação das políticas públicas, traduzindo-se em normas, procedimentos administrativos e em práticas que vão transformando valores e identidades junto aos profissionais docentes. Esse discurso penetra o campo da formação docente e das práticas profissionais no sistema educacional, revelando intencionalidades convergentes com os objetivos da reforma em relação aos processos escolares, determinando novas lógicas de organização e gestão que são parametradas por resultados quantificáveis. Esse processo atua na construção de novas identidades e nas relações de trabalho promovendo a reestruturação da profissão docente.

O procedimento analítico adotado neste artigo foi retirado de um modelo desenvolvido por Popkewitz (1996) para estudo comparativo entre as políticas educativas de quatro países, no qual buscou compreender o processo de regulação do Estado em três níveis: a relação entre atores e discursos nas reformas educativas; as homologias entre a construção do professor e da criança no cenário educativo e as mudanças na política, nas artes e na economia; e a pedagogia como um lugar específico que relaciona as racionalidades políticas com as capacidades dos indivíduos. Nesse terceiro

1 Este artigo é resultado de pesquisa que conta com o apoio do CNPq e do PPM/FAPEMIG. nível, procura demonstrar como a pedagogia produz sistemas de inclusão e exclusão.

A opção por esse modelo analítico repousa na premissa de que, para se compreender as mudanças que ocorrem na profissão docente em um determinado contexto, é necessário ampliar o foco de visão para além da escola, buscando perceber como as políticas educativas gestadas no âmbito do Estado sofrem influências de distintas ordens e vão sendo incorporadas pelos diferentes atores do sistema educacional (e fora dele). Nesse modelo, Popkewitz (1996) procura situar o Estado no marco da problemática da regulação. Para ele, as mudanças no cenário educativo são um exemplo de mudanças na regulação social que se produzem na relação entre atores de organismos governamentais e a sociedade civil.

Importante mudança na relação entre atores e discursos nas reformas educativas pode ser percebida na maneira como a NGP veio sendo adotada por grande parte de países da América Latina desde os anos 1990, reestruturando o Estado por meio de princípios fundamentados na empresa capitalista, sob o argumento de necessária modernização. Ela se insere em um discurso reformista que chega até a escola baseado na eficácia e eficiência nos serviços públicos (OLIVEIRA; DUARTE; CLEMENTINO, 2017).

Essas reformas implementam ações que são guiadas por novas regras e que estabelecem novas formas de pensar o trabalho docente. Muitos estudos (CUENCA, 2015; FELDFEBER; IMEN, 2007; OLIVEIRA, 2004; TENTI-FANFANI, 2005; TERIGI, 2010) produzidos em diferentes países da região demonstram que foram realizadas reformas nos sistemas de formação docente e nas carreiras dos professores a partir dos 1990 que interferem na sua profissionalidade. Essas reformas introduziram, 
via de regra, a avaliação como mecanismo indispensável para obter a melhoria educativa.

Observa-se em estudos mais recentes sobre o tema da profissionalização docente que, em diferentes contextos nacionais, os discursos sobre os professores do setor público apontam para crescente desprofissionalização, que se traduz na desautorização de um modelo de identidade profissional e nos apelos ao "novo profissionalismo" (ANDERSON; HERR, 2015). Diante das reiteradas críticas à escola e aos sistemas educacionais pelo seu baixo desempenho, muito abaixo do que se espera, tendo como referência os parâmetros de rendimento dos estudantes pertencentes aos países membros da Organização de Cooperação e Desenvolvimento Econômico (OCDE), os discursos dirigidos aos professores no contexto latino-americano são no sentido de que se espera que eles compensem os fatores sociais que demandam investimento social.

\section{A NGP no contexto latino-americano e a reforma educacional}

O contexto latino-americano foi marcado, durante a década de 1990, por intensos processos de reforma estatal que, justificada pelas necessidades de ajustes estruturais, alteraram a relação entre Estado e sociedade civil, provocando mudanças substantivas na ação pública, desenvolvendo outros modos de regulação. Essas reformas tiveram como paradigma os critérios da economia privada para a gestão da coisa pública e acabaram promovendo o esmaecimento da noção de público como bem comum e, consequentemente, de direito público, no qual se inscreve a educação.

De acordo com Ball e Youdell (2007), a privatização crescente da educação no mundo é uma tendência comprovada e em muitos casos ela vem encoberta, numa espécie de simulacro. Algumas dessas formas são denominadas diretamente privatização, mas observam os autores que, às vezes, a privatização permanece encoberta, como, por exemplo, nas reformas educativas, em que ela é sempre apresentada por meio de práticas objetivas que buscam soluções eficazes para o atendimento público. Os autores advertem que, em muitos casos, os objetivos políticos declarados se manifestam através de expressões diversas como, por exemplo, escolha, responsabilidade, melhora educativa, transferência de atribuições, competência ou eficácia.

Ball e Youdell (2007) advertem ainda que esse tipo de política pode não se expressar claramente na forma de privatização, mas apoiando em métodos e valores próprios do setor privado, faz com que a educação pública funcione ao estilo de uma empresa privada. Por esta razão, os autores consideram que a privatização da educação pública pode ser de duas naturezas: "endógena" e "exógena". Por privatização endógena entendem as formas que implicam na importação de ideias, métodos e ferramentas da empresa privada. Já a privatização exógena refere-se a formas que envolvem a abertura dos serviços públicos à participação do setor privado, através de modalidades baseadas em benefício econômico.

Alertam ainda os autores que as tendências para a privatização da educação pública servem muitas vezes para preparar o caminho para formas explícitas de privatização, incluindo, por exemplo, o uso direto de empresas privadas para prestar serviços educativos.

A NGP pode ser considerada um tipo de privatização endógena, sendo uma forma indireta que introduz valores da economia privada na gestão pública. Tendo sempre como referência a empresa privada, a NGP vai impondo um ethos empresarial na gestão dos serviços públicos, imprimindo uma lógica mercantil entre fornecedores e clientes ou consumidores, onde antes imperavam noções de direito baseadas na relação entre Estado e cidadania.

De acordo com Gruening (2001), o movimento da NGP começou em fins dos anos 1970 e começo dos anos 1980. Seus primeiros praticantes emergiram no Reino Unido, sob o governo da Primeira Ministra Margaret Thatcher e nas administrações municipais dos Estados Unidos (por exemplo, na Califórnia) que mais haviam sofrido com a recessão econômica e reajustes fiscais. Em seguida, os governos da Nova Zelândia e da Austrália se juntaram a esse movimento. $\mathrm{O}$ êxito dessas experiências fez da NGP um modelo de reforma administrativa que ganhou a maior parte dos países da Europa e da América Latina.

A NGP, que surge então nas últimas décadas do século XX como um movimento crítico à organi- 
zação estatal-burocrática, pode ser caracterizada de forma genérica pelos seguintes princípios: dissociação das funções de execução e controle; fragmentação das burocracias e sua abertura às demandas e exigências dos usuários; concorrência de atores públicos com o setor privado e a terceirização dos serviços; reforço das responsabilidades e da autonomia dos níveis de execução da ação pública; gestão por resultados e a contratação com o estabelecimento de metas e objetivos e a avaliação de desempenho; normalização, via padronização, das práticas profissionais baseadas em evidências e em experimentos exemplares (DEMAZIÈRE; LESSARD; MORRISSETE, 2013)

As reformas sofridas pela educação na região latino-americana nos anos 1990, a despeito de terem sido realizadas em sua maioria por governos de orientação neoliberal, foram justificadas pela necessária expansão da cobertura educacional. Para tanto, a questão da gestão e do financiamento público ocupou o centro do debate. A preocupação em tentar fazer mais com menos, ou seja, extender a cobertura educacional sem ampliar na mesma proporção o orçamento público, dirigiu o processo para maior aproximação com o setor privado em muitos sentidos, envolvendo desde a busca de apoio fora do Estado até a incorporação por ele da lógica produtiva. Esse processo esteve guiado por políticas de desregulamentação, descentralização e flexibilização que implicaram em reformas do Estado (SALAMA; VALIER, 1997), promovendo o que ficou conhecido como a NGP. Essas reformas imbuídas da necessidade do reconhecimento à diversidade, traduzido no lema "Educação para todos", contribuíram para o rompimento com o paradigma universal das políticas sociais vigentes no modelo anterior.

No setor educacional a NGP tem o foco dirigido à gestão escolar, buscando maior eficiência no gasto dos recursos para a ampliação do atendimento público (OLIVEIRA, 1997). Documento publicado pela Comissão Econômica para América Latina e Caribe (Cepal) e Oficina Regional de Educação para a América Latina da Organização das Nações Unidas para a Educação, Ciência e Cultura (OREALC/Unesco), de 2005, intitulado Invertir mejor para invertir más. Financiamiento y gestión de la educación en América Latina y el Caribe (COMI-
SIÓN ECONÓMICA PARA AMÉRICA LATINA Y EL CARIBE; ORGANIZACIÓN DE LAS NACIONES UNIDAS PARA LA EDUCACIÓN, LA CIENCIA Y LA CULTURA, 2005), explicita claramente essa orientação.

A introdução da NGP por essas reformas veio acompanhada de forte retórica valorizando as noções de coletividade, autonomia, flexibilidade e participação, como se pode observar em muitos documentos produzidos por organismos internacionais como o supracitado Unesco/Cepal (2005). Entretanto, a partir desse momento a discussão sobre a qualidade se torna um imperativo nas políticas de educação, fomentando processos de avaliação em larga escala.

A disseminação da NGP tem sido um processo amplo que atinge um número considerável de países. Verger e Normand (2015) assinalam que, nos últimos anos, a NGP tem penetrado com força a agenda educativa global, por ser esse um setor com destacada dotação orçamentária. Afirmam ainda que, onde foi aplicada, a NGP alterou de maneira drástica a forma como se concebe a governança das instituições educativas, já que princípios como a autonomia escolar, a prestação de contas, a gestão baseada em resultados e a liberdade de escolha escolar têm penetrado profundamente em como se regulam, proveem e financiam os serviços educativos.

Apresentada como uma forma inovadora de gerir as instituições públicas, atribuindo-lhes maior eficiência, a NGP, ao fazê-lo, acaba por interferir no sentido da prestação de serviços públicos, provocando mudanças no coração da relação entre Estado e cidadania. Como afirmam Popkewitz e Lindblad (2001), as novas abordagens da gestão pública não renovam apenas o contrato social, elas encarnam também um conjunto de relações que investe o indivíduo de capacidades e habilidades particulares. Trata-se de uma reconstrução do Estado em relação à sociedade civil, nomeada de parceria, em que o envolvimento e o engajamento dos atores sociais, em nível individual e coletivo, são constantemente buscados, tendo por objetivo encontrar soluções locais para problemas que são muitas vezes de ordem geral. Assim como com os conceitos de coletividade e colegialidade, buscando recriar a noção de um "nós" comprometido com 
os resultados da ação pública, com a eficácia da execução das políticas.

No caso brasileiro, a incorporação do empresariado nacional nos debates educacionais a partir da década de 1990 merece destaque, envolvendo novas formas de contratação com a sociedade (OLIVEIRA, 2000), intensificando-se na década seguinte, o que ficou mais evidente com a criação do movimento Todos pela Educação (TPE). Contudo, em muitos países da América Latina se observa a mesma interlocução entre governos e empresariado. O movimento dos empresários pela educação se constitui em forte rede que busca influenciar as políticas nacionais na região, atribuindo-lhes cada vez mais um sentido produtivo que se referencia no setor privado.

Como destacam Ball e Youdell (2007, p. 03), as formas diversas de privatização modificam a maneira como se organiza, se gestiona e se oferta a educação: "la manera en que se deciden y enseñan los planes de estudio, la manera en que se evalúan los resultados de los alumnos y, por último, la manera en como se juzga a los estudiantes, los profesores, los centros docentes y las comunidades locales".

São formas que também interferem na maneira como se preparam profissionalmente os docentes e como se organiza seu trabalho:

Las tendencias de la privatización modifican la forma en que se preparan los profesores, la naturaleza del desarrollo profesional en vigor y de su acceso a él, las condiciones de los contratos y de las retribuciones del personal docente, la naturaleza de las actividades diarias de los enseñantes y la manera en que éstos perciben sus vidas laborales. La 'flexibilización' del trabajo del personal docente es uno de los componentes fundamentales de la mayor parte de las manifestaciones de la privatización, que amenaza con alterar la idea que la sociedad tiene de los enseñantes, así como la calidad de los conocimientos y las habilidades aprendidas por los alumnos en los centros educativos. (BALL; YOUDELL, 2007, p. 03).

Com o avanço da privatização da educação e as recorrentes críticas dirigidas ao setor público estatal como um todo, o estatuto do servidor público tem se degradado nas últimas décadas na maioria dos países da região, como apontam alguns estudos (CAMARGO; JACOMINI, 2011;
CUENCA, 2015). Esse processo tem resultado em perda da estabilidade no emprego, diminuição de concursos públicos, achatamento salarial e corrosão das carreiras, falta de perspectivas de promoção, entre outros. São processos de desestabilização, desinvestimento e mercantilização que impactam diretamente as relações de trabalho dos docentes, promovendo uma reestruturação da profissão.

Assim, observa-se como o processo de regulação que vai lentamente alterando a relação entre Estado e sociedade civil desce do primeiro nível do discurso acerca da reforma, da necessidade de reestruturar as políticas públicas em geral e as políticas específicas de educação, e chega ao segundo nível, apontado por Popkewitz (1996), do domínio da construção dos professores, procurando pôr em prática as novas lógicas reformadoras, interferindo na forma como são preparados os docentes e como se estruturam suas relações de trabalho.

\section{A reestruturação da profissão docente e a emergência do "novo profissionalismo"}

As mudanças ocorridas na profissão docente em decorrência do desenvolvimento da NGP nos países latino-americanos apresentam dimensões variadas. Diretamente ligado ao processo de trabalho, observa-se a intensificação das atividades em escalas diferentes e a incorporação de lógicas próprias da organização capitalista na gestão da escola pública. Com especial destaque para a adoção de incentivos econômicos articulados aos processos de avaliação, que têm sido introduzidos pelas políticas de accountability nos sistemas públicos de ensino, observa-se um achatamento salarial que é parcialmente compensado por prêmios e bonificações (DUARTE, 2013).

Cuenca (2015), em estudo intitulado Las carreras docentes en América Latina. La acción meritocrática para el desarollo profesional, produzido para a OREALC/Unesco, oferece importantes aportes para se conhecer as mudanças que afetam a profissão docente na região. $\mathrm{O}$ estudo trata sobre as regulações concernentes à carreira em 18 países da região, tendo em vista analisar quatro eixos: os mecanismos de acesso à carreira docente, as estratégias de promoção laboral; os processos de 
avaliação da função docente e os procedimentos de saída da carreira; e, ainda, os programas de incentivos e estímulos ao trabalho docente.

Com esse estudo, o autor conclui que as carreiras docentes latino-americanas são plataformas legais heterogêneas quanto à sua natureza jurídica, orientação técnica e organização interna. Isto se deve ao extenso período de tempo que abarcam estas regu- lações. Constata que coexistem na região carreiras que foram desenhadas e aprovadas nos anos 1950 até as que obedecem a regulamentação muito recente. Para fins de análise, Cuenca (2015) organiza as carreiras docentes latino-americanas em três grupos, a partir de duas características: a amplitude e a extensão da carreira, medida desde as estratégias de promoção horizontal e vertical; e a incorporação de mecanismos de avaliação com consequencias de alto impacto; ou seja, nas suas palavras: "evaluaciones del desempeño de los maestros que pueden devenir en la pérdida de la estabilidad laboral." (CUENCA, 2015, p. 09).

No primeiro grupo de carreiras se encontram a maioria, as quais a dinâmica da carreira está baseada em critérios como a antiguidade e a acumulação de certificados. Para esse grupo não só estão previstas a avaliação de desempenho, mas também a estabilidade no emprego assegurada pelo Estado. No segundo grupo se encontram aquelas carreiras que estão fundamentadas no que o autor denomina de primeira geração, mas que também apresentam algumas características próprias das novas carreiras, na maioria dos casos são características vinculadas com a avaliação de desempenho. A segunda geração de carreiras compõe o terceiro grupo, são as mais recentes e estão desenhadas de acordo com enfoques estritamente meritocráticos. Nessas carreiras a estabilidade laboral está associada aos resultados de avaliações de desempenho e tendem a privilegiar a promoção horizontal (CUENCA, 2015, p. 10).

Essas reestruturações na carreira guardam relação com a forma como os docentes são considerados na sociedade contemporânea e como eles próprios concebem seu trabalho e sua profissão. Malet (2009) constata, com base em revisão de literatura, que as reformas conduzidas na Inglaterra e nos Estados Unidos resultaram em empobrecimento e perversão de uma profissionalidade docente nas suas dimensões moral, ética e crítica, nas quais se tinha construído sua legitimidade social. Fenômeno parecido é observado na região latino-americana em diferentes estudos (BIRGIN, 2000; OLIVEIRA, 2004; TENTI-FANFANI, 2005).

A discussão acerca da reestruturação da profissão docente pressupõe uma estruturação anterior, uma parametrização, sob a qual erigiu-se um corpus configurado, no seu sentido estrito de dar aparência externa a um corpo, fundamentado em determinada perícia ou saber-fazer reconhecido, regido por um código deontológico e estatuto profissional. Para a região latino-americana, pode-se considerar como marco dessa estruturação a Recomendação da Organização Internacional do Trabalho (OIT) e Unesco de 1966 relativa ao Estatuto dos Professores (ORGANIZAÇÃO INTERNACIONAL DO TRABALHO; ORGANIZAÇÃO DAS NAÇÕES UNIDAS PARA A EDUCACIÓN, A CIENCIA E A CULTURA, 1966). Essa recomendação foi aprovada na Conferência Intergovernamental Especial sobre a Condição dos Professores. Ela está fundamentada na constatação de que o direito à educação é um dos direitos fundamentais do homem, que é de responsabilidade dos Estados assegurarem a todos uma educação adequada, conforme o Artigo 26 da Declaração Universal dos Direitos do Homem e os Princípios números 5, 7 e 10 da Declaração dos Direitos da Criança e da Declaração das Nações Unidas relativa à Promoção dos Ideais de Paz, de Respeito Mútuo e Entendimento entre os Povos.

A Recomendação se justifica pela necessidade de um aumento e alargamento do ensino geral e do ensino técnico e profissional, com vista à utilização plena de todas as aptidões e recursos intelectuais existentes, como condição necessária à promoção dos valores morais e culturais e à continuidade do progresso econômico e social,

[...] reconhecendo o papel essencial dos professores no progresso da educação e a importancia do seu contributo para o desenvolvimento do homem e da sociedade moderna, visando assegurar ao pessoal docente uma condição que esteja de acordo com esse papel. (ORGANIZAÇÃO INTERNACIONAL DO TRABALHO; ORGANIZAÇÃO DAS NAÇÕES UNIDAS PARA A EDUCACIÓN, A CIENCIA E A CULTURA, 1966, p. 01). 
Essa Recomendação surge como uma necessidade de orientar os estados nacionais, levando em conta a grande diversidade de legislações, regulamentos e usos que nos diferentes países definem as estruturas e a organização do ensino. Nessa direção, traz em seus argumentos, tomando igualmente em conta as recomendações relativas a vários aspectos da formação e da condição do professor das escolas primárias e secundárias, o desejo de

[...] melhorar as normas existentes por meio de disposições suplementares relativas aos problemas de particular importância para o pessoal docente e, em particular, remediar as consequencia da sua escassez. Nesse sentido é que se aprova a Recomendação em que se define:

a) O termo «pessoal docente» ou «professores» serve para designar todas as pessoas encarregadas da educação dos alunos.

b) O termo «condição» empregado em relação ao pessoal docente, designa, tanto a posição social que se reconhece segundo o grau de consideração atribuído à importancia da função, e à competência e condições de trabalho, como pela remuneração e demais benefícios materiais que se lhe concedem, em comparação com outras profissões. (ORGANIZAÇÃO INTERNACIONAL DO TRABALHO; ORGANIZAÇÃO DAS NAÇÕES UNIDAS PARA A EDUCACIÓN, A CIENCIA E A CULTURA, 1966: p. 01).

Considerando que a maioria dos países da América Latina só tiveram seus sistemas escolares organizados e consolidados em meados do século XX, essa Recomendação pode ser tomada como um importante guia de orientação para a profissão docente tanto no que se refere à ação do Estado, quanto dos próprios profissionais por meio de suas entidades representativas. Estão dispostas na citada Recomendação orientações com relação: a) à política de ingresso do pessoal docente; b) às contratações e carreiras profissional; c) à ascessão e promoção; d) às atribuições complementárias; e) aos direitos e obrigações; f) às condições para um ensino eficaz (em que se sugere definir o número suficientemente reduzido de alunos por classe para garantir que o profissional docente possa se ocupar pessoalmente e de maneira eficiente de cada um); g) à remuneração; h) à colaboração na determinação da política escolar; i) às negociações entre as organizações de empregadores e de educadores; j) à escassez de pessoal docente (ORGANIZAÇÃO INTERNACIONAL DO TRABALHO; ORGANIZAÇÃO DAS NAÇÕES UNIDAS PARAA EDUCACIÓN, A CIENCIA E A CULTURA, 1966).

O papel das associações gremiais e sindicatos é garantido, e em certa medida reforçado, nessas orientações, sobretudo no item "i", que se refere ao princípio da negociação coletiva para a determinação dos salários e condições de trabalho.

De acordo com Tiramonti (2001), a partir de pesquisa realizada em um conjunto de países da região compreendendo Argentina, Brasil, Colômbia, Costa Rica, Chile, El Salvador, Guatemala, México, República Dominicana e Venezuela, o papel que tiveram os sindicatos docentes na consolidação dos sistemas educativos nacionais é destacável. A autora afirma que esses países contaram com a participação efetiva dos sindicatos em diferentes momentos, de acordo com o desenvolvimento de seus sistemas educativos, na elaboração de normas e regulamentação do setor. Destaca ainda a forte presença dos sindicatos no desenho dos estatutos docentes e em ocasião de recuperação dos regimes democráticos, em que estiveram presentes na renovação dos corpos normativos (TIRAMONTI, 2001).

A Recomendação de 1966, supracitada, representa uma iniciativa de organismos internacionais, neste caso específico a Unesco e a OIT, de interferir por meio de orientação técnica, mas claramente política, na organização da agenda educativa global. Contém uma preocupação expressa de que era necessário tratar a educação, que se revestia naquele momento de um caráter universal, a despeito das especificidades regionais, propondo-se a contribuir para o estudo e ação do tema em escala internacional, como pode ser constatado no extrato a seguir:

El tema reviste, pues, un carácter de universalidad; se presta al estudio y a la acción en la escala internacional, a la investigación de principios y normas de carácter general, susceptibles de inspirar y, en un momento dado, de orientar la acción internacional. Esta consideración tiene, al parecer, uma significación especial para los países en vías de desarrollo económico que se ven obligados a edificar y ampliar progresivamente sus sistemas escolares generales y profesionales en función de 
sus necesidades económicas y sociales actuales y futuras $y$ de los medios de que disponen para tal fin. (ORGANIZAÇÃO INTERNACIONAL DO TRABALHO; ORGANIZAÇÃO DAS NAÇÕES UNIDAS PARA A EDUCACIÓN, A CIENCIA E A CULTURA, 1966, p. 01).

A participação dos organismos internacionais na definição de uma agenda regional para os países da América Latina pode ser documentada desde uma década antes da referida Recomendação de 1966. Já em 1958, com o Seminário Interamericano sobre Planejamento Integral da Educação, realizado em Washington, sob os auspícios da Organização dos Estados Americanos (OEA) e da Unesco, foi acordado a iniciativa de organizar a Conferencia Inter-americana sobre Educación e Desarrollo Económico y Social, que ocorreu em Santiago do Chile, em março de 1962, com a participação da Cepal, da OIT, da Organização das Nações Unidas para a Alimentação e Agricultura (FAO) e da Organização Mundial de Saúde (OMS).

Tomando a ideia de que a reforma educacional é um fenômeno global e que ela vem se desenvolvendo em escala internacional, a partir das últimas décadas do século XX, é importante observar como as políticas educativas nacionais absorvem e interpretam as influências trazidas de fora e o papel que jogam esses organismos na difusão dessas políticas.

Alguns autores têm discutido como a governação por números vem se tornando uma constante na agenda global em educação. Grek (2016) destaca que o espaço da política europeia de educação não foi determinado apenas pelos limites geográficos de um mercado comum. De acordo com a autora, já em 1960, essa intenção já se expressava em um projeto compartilhado e um espaço de sentido, construído em torno de valores culturais e educacionais comuns, a partir da década de 1960 até a década de 1970. Ressalta, porém, que o discurso de uma cultura comum e histórias compartilhadas foi lentamente sendo produzido como um conjunto de fatos e mitos sobre uma "comunidade imaginada" europeia, renascendo das cinzas de uma Segunda Guerra Mundial destrutiva. Assim, a formulação de políticas de educação para a "Europa dos cidadãos" assumiu a forma de cooperação cultural, mobilidade dos estudantes, harmonização dos sistemas de qualificação e formação profissional, o que foi concretizado e perseguido por meio de programas comunitários, tais como Comett e Erasmus. Grek (2016, p. 712) ressalta que,

[...] independentemente dos seus efeitos relativamente limitados, o projeto de uma 'Europa dos cidadãos' tinha uma ambição clara: criar identidade e cultura europeias distintas - e usar esses recursos para permitir a governança de um espaço cultural e político compartilhado.

Entretanto, para Grek (2016), foram eventos determinantes que transformaram o espaço europeu da educação, de um projeto um tanto idealista de coesão cultural, em uma realidade competitiva muito mais incisiva. Isso porque, seguindo esses primórdios, o discurso sobre fundamentos culturais iria mudar para um discurso de medição. Dessa forma, a autora demonstra que,

[...] na virada do milênio, a meta de uma economia do conhecimento e o problema da governança do mercado estavam se movendo para além da mobilização, sistematização e colaborações de trabalho nas arenas da educação profissionalizante e superior. A educação poderia agora sair das sombras da construção de uma cultura e de uma identidade comum para '[a] construção gradativa de um espaço educacional europeu aberto e dinâmico'. (GREK, 2016, p. 713).

Para ela, os formuladores de políticas tornaram-se muito mais interessados nos resultados dos sistemas de ensino do que nos insumos. Essa mudança da políticacentrou-se em informações dos sistemas europeu e nacional e no progresso em direção a objetivos comuns, e envolveu uma série de novos atores nas cidades, empresas e parcerias público-privadas.

De acordo com Pettersson (2014 apud PETTERSSON; MOLSTAD, 2016), a despeito de a OCDE estar primeiramente preocupada com políticas econômicas, a educação tem se tornado cada vez mais importante na sua agenda devido ao fato de que, ao longo dos últimos 40 anos, a educação foi reformulada para incluir a competitividade econômica, em um discurso econômico relacionado com o capital humano e com a "economia do conhecimento.

A tendência observada por Grek (2016) em relação ao espaço europeu oferece aportes para a análise da região latino-americana. O papel central 
que desempenhou a Unesco na orientação das políticas educativas na região durante os anos 1960 até os anos 1980, sendo paulatinamente substituída pela influência crescente do Banco Mundial no final dos anos 1980 e durante toda a década de 1990, e na atualidade a crescente participação da OCDE por meio da prova PISA e da pesquisa TALIS, demonstram como as influências trazidas por esses organismos estão a serviço de produzir um espaço comum, quer no sentido da comparabilidade e concorrência, quer no sentido de integração e convergência a um projeto em escala internacional.

\section{A emergência do "novo profissionalismo" e a escolarização centrada nas aprendizagens}

A reestruturação da profissão docente como resultado dos processos de reforma de Estado orientados pelos princípios da NGP demonstra ser convergente aos novos padrões de escolarização impostos pela dita "sociedade do conhecimento", expressando o que seria o terceiro nível da regulação apontado por Popkewitz (1996). Segundo Pettersson e Molstad (2016), no discurso global sobre educação o docente é sempre considerado essencial ao sucesso e à eficácia da aprendizagem. Eles demonstram, por exemplo, que nos relatórios do PISA os bons professores e o ensino eficaz se apresentam como estratégias que permitem que os alunos socialmente desfavorecidos possam acompanhar os alunos melhor favorecidos e, desta forma, promover um efeito de maior equalização.

Os autores procuram demonstrar, assim, que o PISA constrói uma visão específica da maneira como os docentes devem ensinar e como eles são concebidos. E ainda, como os docentes são modelados e fabricados por um tipo de discurso que atinge em diferentes níveis o sistema educativo.

$\mathrm{O}$ discurso contruído pelos organismos internacionais para as reformas educativas na região latino-americana, com especial destaque para o papel que cumpriram a Unesco e a Cepal durante a segunda metade do século XX, e, em especial, o Banco Mundial na década de 1990, que atuou sobre os professores no sentido apontado por Pettersson e Molstad (2016), variando com o passar do tempo de um modelo fundamentado no estatuto profissional- -burocrático a um modelo flexivel e responsivo, baseado no Desenvolvimento Profissional Docente (DPD). Esses discursos tendem a interferir na compreensão da profissionalização docente pelos próprios profissionais e suas entidades representativas, mas principalmente influenciam políticas que interferem nas condições objetivas do exercício profissional em educação.

Em geral, a profissionalização é tomada pelos sujeitos como um objetivo, uma estratégia de valorização, como o ato de profissionalizar-se. A progressão dentro de uma direção dada e de uma determinada temporalidade, a evolução de uma gradação, ao que se assemelha a noção de carreira, numa progressão positiva e desejável que define o que seria o processo de profissionalização.

De acordo com Demazière, Roquet e Wittorski (2012), a profissionalização é um curioso fenômeno para as ciências humanas e sociais, por designar numerosas mutações do mundo do trabalho e da formação, tornando-se uma questão incontornável para os que a descrevem, analisam, compreendem, e interpretam suas transformações. Esses autores procuram interrogar e teorizar em nome de uma exigência analítica e de uma postura interpretativa que tenta compreender a variedade de significados que ela tem no senso comum e os seus usos sociais. Compreendem esses autores que, de um lado ela concerne o processo de divisão do trabalho nos seus aspectos mais estruturantes, a especialização das atividades produtivas, reconhecimento do ofício, diferenciação de estatutos, autonomização de grupos profissionais, entre outras. De outro lado, a profissionalização se instala no campo da formação articulando-se com os requisitos para obtenção de empregos e objetivos formativos (currículos profissionalizantes, definição de saberes etc.).

Numa visão normativa, a profissionalização é tida como um conjunto de tarefas que são atribuídas a um ofício e que tendem a responder a uma demanda no mercado de serviços ou produtos, a preencher posições sociais por meio do emprego. Segundo Rodrigues (2002), o conceito de profissão pode ser aceito como uma ocupação que exerce autoridade e jurisdição exclusiva, simultaneamente sobre uma área de atividade e de formação ou conhecimento, tendo convencido o público de que os seus serviços são os únicos aceitáveis. O que se assemelha 
ao sistema perito descrito por Giddens (2002), em que as profissões cumprem importante papel nessa sociedade à medida que contribuem para instaurar a confiança por meio de fichas simbólicas.

Demazière, Roquet e Wittorski (2012) consideram que a profissionalização é sempre inacabada e um debate em aberto. Esses autores ressaltam que a profissionalização é concebida como uma categoria gestionária ou administrativa, constituída como vetor de demandas dirigidas aos trabalhadores a proposito do que eles fazem, envolvendo questões e exigências de preparação para o exercício profissional. Nesse sentido, a profissionalização remete à produção e transmissão de saberes e seu reconhecimento como competências negociáveis. Ela está muito mais focada nos resultados, no produto do trabalho. Atender a clientes ou consumidores preocupados com a qualidade dos bens ou serviços que eles adquirem, como ter uma garantia superior. Desse modo, os debates sobre a profissionalização encontram convergência com as tendências observadas na NGP.

Para os mesmos autores, a profissionalização é em efeito um trabalho, no qual são desenvolvidas as interações, as mudanças, os conflitos, as negociações que implicam uma multiciplidade de atores. Assim, ela pode ser considerada um processo dialético, que implica de uma parte os sujeitos envolvidos, ou seja, os profissionais trabalhando, se formando e se destinando, e, de outra, aqueles que estão envolvidos no quadro dessa profissionalidade.

Pode-se considerar, então, que a história de organização e constituição da profissão docente esteve marcada por um processo constante de um devir a ser que enfrenta fortes obstáculos, sobretudo por aspectos considerados indispensáveis para essa condição: autonomia, controle sobre o recrutamento, monopólio, estatuto único, entre outros. Na atualidade, outros desafios se somam ou se sobrepõem aos já existentes, em especial a ampliação das expectativas sobre os resultados escolares e a instabilidade trazida pelas novas condições de emprego e trabalho (OLIVEIRA, 2002), revestidas de forte retórica em torno da noção de profissionalismo.

Antes de aprofundar as discussões sobre profissionalismo docente, seria útil mencionar a distinção entre os termos "profissionalismo" e "profissionali- zação", já que, em geral, acompanham um ao outro nos discursos políticos e nas pesquisas acadêmicas.

De maneira resumida, pode-se afirmar que a profissionalização está relacionada à "promoção dos interesses materiais e ideais de um grupo ocupacional" (GOODSON, 2000 apud DEMIRKASIMOGLU, 2010, p. 182) e que ainda inclui "a tentativa de obter participação profissional" (WHITTY, 2000 apud DEMIRKASIMOGLU, 2010, p. 182). Já o conceito de profissionalismo é definido de várias formas e, dependendo do ponto de vista e das diferentes perspectivas, pode estar associado com a definição de profissão.

De acordo com Demirkasimoglu (2010), uma primeira vertente explica o profissionalismo como a necessidade de alcançar e desenvolver certos padrões e critérios de competitividade para as profissões no mercado de trabalho atual, possibilitando a definição de padrões de ambiente profissional e de procedimentos baseados na busca de "melhores práticas". O discurso em torno da defesa do "novo profissionalismo" é de permitir que as organizações criem sistemas, políticas e procedimentos com confiança; eles também querem garantir alta qualidade operacional (KRISHNAVENI VE ANITHA, 2007 apud DEMIRKASIMOGLU, 2010). Essa busca está relacionada na atualidade à eficácia na vida profissional. De forma genérica, o termo profissionalismo aparece relacionado à competência, ao que é necessário para o exercício bem-sucedido da ocupação (ENGLUND, 1996 apud DEMIRKASIMOGLU, 2010).

Para outros autores, o profissionalismo pode ser percebido como um movimento que parte dos próprios atores profissionais. Nesse sentido, Hoyle (2001 apud DEMIRKASIMOGLU, 2010) define o profissionalismo como aquelas estratégias e retóricas empregadas por membros de uma corporação buscando melhorar o status, o salário e as condições em que trabalham. Para esse autor, o profissionalismo está relacionado à qualidade do serviço e não à melhoria do status. Há também os que acreditam que o profissionalismo está ligado à ideia de que os atores prestam um importante serviço público, que possuem especialização, expressam dimensão prática distinta que exige um código de ética, requerem e exigem profissionais com alto grau de autonomia individual - independência de 
julgamento - para a prática efetiva (DAVID, 2000 apud DEMIRKASIMOGLU, 2010). Desse modo, a autonomia é um dos principais focos das características do profissionalismo.

Tendo em conta as diferentes abordagens sobre o profissionalismo docente nos debates acadêmicos, percebe-se que os significados que lhe são atribuídos apresentam característica dinâmica e, às vezes, controversa. Este dinamismo e a variação de interpetações que comporta são resultantes das mudanças políticas e sociais que atuam sobre a profissão docente em seus contextos históricos. Interpretações contemporâneas do profissionalismo docente e defesa de noções anteriores, baseadas na estabilidade e em estatuto mais rígido, podem ser compreendidas como medidas defensivas no sentido de que os professores enfrentam múltiplas pressões, e que viram ser intensificado o controle ocupacional sobre eles nos últimos tempos.

Os discursos dominantes no campo da educação, em especial aqueles difundidos por organismos internacionais como Unesco, Banco Mundial e OCDE, apresentam o profissionalismo docente como um fator necessário à melhoria da qualidade da educação e da imagem pública desses profissionais.

No documento da Organization for Economic Co-operation and Development (2005) é possível perceber como são amplas as expectativas e sérios os compromissos que deposita sobre os professores na atualidade, devendo estes responder de maneira eficaz às demandas dos alunos e ao mesmo tempo demonstrar sensibilidade em releação às questões culturais e de igualdade de gênero, e fomentar a tolerância.

Ao trazer o foco para a América Latina, o teor do discurso não muda muito. Em recente relatório sobre a formação docente na região, produzido pela Unesco (VAILLANT, 2013, p. 187), tem-se a seguinte constatação:

Entre los desafíos y dilemas comunes a varios países de la región, aparece la preocupación por atraer estudiantes con mejores condiciones para un buen desempeño profesional, elevar la calidad de la formación inicial del profesorado, fortalecer la formación continua, promover carreras que incidan en el desarrollo profesional y garanticen remuneraciones adecuadas y condiciones para un trabajo docente efectivo, y sistemas de evaluación de desempeño basados en estándares.

Entretanto, esse último documento entende que o entorno profissional apresenta problemas, tais como dificuldades para reter os "bons professores" e novos docentes sendo vistos como deficitários em relação às expectativas a respeito de seu desempenho. Reconhece ainda que são escassos os estímulos para que a profissão docente seja a primeira opção de carreira entre os jovens ingressantes na educação superior, além de constatar que as condições de trabalho são inadequadas e apresentam sérios problemas na estrutura de remunerações e incentivos. Constatações muito próximas e até mais incisivas são encontradas em documento produzido pelo Banco Mundial para a região latino-americana, intitulado Professores excelentes, em que se observa textualmente:

A evidência disponível sugere que a América Latina não está atraindo as pessoas de alto calibre de que precisa para construir sistemas educacionais de classe mundial. Praticamente todos os países da região parecem estar presos em uma armadilha de equilíbrio de nível baixo, com baixos padrões para o ingresso no magistério, candidatos de baixa qualidade, salários relativamente baixos e com pouca diferenciação, pouco profissionalismo em sala de aula e resultados educacionais deficientes. Será difícil passar para um novo equilíbrio. Nenhum sistema escolar da América Latina hoje, com exceção talvez de Cuba, está muito próximo de padrões elevados, elevado talento acadêmico, remuneração alta ou, pelo menos adequada, e grande autonomia profissional, que caracterizam os sistemas educacionais mais exitosos do mundo (como os encontrados na Finlândia; Cingapura; Xangai; China; Coreia; Suíça; Holanda e Canadá). (BRUNS; LUQUE, 2014, p. 10).

Entretanto, em um contexto dominado pela NGP e pelas políticas de accountability que cada vez mais se afirmam na região, por meio do apelo moral de dar resposta à sociedade de como são gastos os recursos públicos em educação, valendo-se para tanto dos resultados acadêmicos como produto material, o que se observa é a defesa da modernização das profissões por meio do "novo profissionalismo" materializado nas políticas de DPD.

As políticas atuais que instituem a negociação permanente das regras locais, o atingimento de me- 
tas de desempenho em contraposição aos critérios tradicionais dos estatutos profissionais - que se baseiam na estabilidade, na progressão hierárquica e na valorização dos títulos e da experiência -, é defendida por importantes segmentos que influem na agenda educativa da região. A defesa de formas de remuneração baseadas em incentivos vinculados a uma avaliação meritocrática é apresentada por esses setores como forma de melhorar o desempenho e garantir a aprendizagem:

Os sistemas eficazes de avaliação de professores fortalecem a responsabilização. Eles permitem que os gestores dos sistemas escolares identifiquem os professores com necessidade de aprimoramento e criem fortes incentivos para que esses professores busquem o treinamento oferecido e o apliquem ao seu trabalho. (BRUNS; LUQUE, 2014, p. 35).

Contudo, o que se constata a partir dos estudos realizados nas distintas realidades nacionais da região é que:

En nombre de la modernización, la tarea de enseñar incorporó paquetes tecnológicos que contribuyeron al fortalecimiento del trabajo y prometeron un camino de desarrollo profesional; pero también, modificaron sustantivamente el sentido de enseñar. Factores tales como el auge de la psicología cognitiva, el desarrollo de las ideas construcvistas y el enfoque educativo basado en el aprendizaje, originaron que los docentes perdiesen su referente tradicional de trabajo. (CUENCA, 2015, p. 10).

Para esse autor, as reformas nas políticas de formação docente e salariais não alcançaram os resultados esperados porque foram realizadas de forma desarticulada de uma visão global de desenvolvimento profissional, dentro de uma orientação em que se busca "bons professores para ensinar melhor" (CUENCA, 2015). A naturalização da noção de "bons professores" e "boas práticas", inclusive junto a esses profissionais, reforça a ideia de que a maioria não desempenha bem seu ofício, já que não garante a aprendizagem dos alunos. Esse discurso é tomado de forma acrítica por amplos setores da sociedade e se instala no chão da sala de aula.

A depreciação dos docentes no contexto latino-americano em reiterados informes analíticos produzidos por organismos internacionais tem contribuído para uma perda maior de direitos e um avanço brutal de formas desregulamentadoras de contratação e remuneração no setor educacional. Os professores são constantemente mal avaliados por sua origem social, por sua formação inicial, pela ausência de formação continuada ou por seu exercício profissional, ainda que, muitas vezes, sem as necessárias evidências para promover tais juízos. Como exemplo: "a lo largo de estos últimos años en América Latina, es que la formación inicial ha tenido resultados más bien mediocres, a pesar de que se le reconoce un papel clave en los cambios e innovaciones" (VAILLANT, 2010, p. 545)

Ou ainda, como no já citado Professores excelentes:

Devido ao fraco domínio de conteúdo de muitos professores da América Latina e do Caribe, a capacitação nessa área também é claramente importante. Infelizmente, não há evidência de avaliação rigorosa de programas bem-sucedidos da América Latina e do Caribe. (BRUNS; LUQUE, 2014, p. 37).

Concentra-se a crítica e a atenção nos programas de formação, nos currículos dos cursos de formação de professores, como se ao moldar os professores por meio das instituições que os formam se estaria garantindo os objetivos da escolarização com qualidade. Essas são críticas simplistas que ignoram importantes aspectos da questão.

\section{Nova governação, novo profissionalismo para novas aprendizagens: consequências sobre os docentes}

Múltiplas abordagens são comuns no sentido de que o profissionalismo docente significa cumprir certos padrões de educação e proficiência. No entanto, o significado do termo é altamente problemático e polarizado em várias esferas.

Evans (2007 apud DEMIRKASIMOGLU, 2010) observa que uma característica comum de muitas concepções de novo profissionalismo é um foco no controle e proatividade do praticante. Algumas dessas oposições são ideológicas, sendo inclusive utilizadas para promover a noção de contenção e cortes de gastos públicos. O autor conclui que existe um consenso em grande medida de que o propósito da defesa do profissionalismo docente 
na atualidade estaria a serviço do controle ocupacional e autorização de professores, intensificando as demandas de trabalho.

As reformas ocorridas na região a partir da década de 1990 desenvolveram estratégias de manipulação das identidades docentes, valendo-se muitas vezes de um discurso que apela para o profissionalismo. Como compreendido por Ozga (1995 apud DEMIRKASIMOGLU, 2010), o profissionalismo pode ser interpretado em seu contex to histórico como um dispositivo de controle profissional. Nesse sentido, o profissionalismo pode ser tomado como uma construção ideológica para representar e mobilizar interesses particulares, como afirmam Stevenson, Carter e Passy (2007 apud DEMIRKASIMOGLU, 2010).

Lawn (2001) afirma que o profissionalismo poderia operar como estratégia de controle dos professores manipulados pelo Estado, ao mesmo tempo em que é utilizado por eles para proteger-se contra sua diluição. O que pode explicar, em grande medida, a aceitação e incorporação pelos professores, e até mesmo pelos sindicatos docentes, do discurso reformador, assim como a naturalização das práticas que são forjadas por estas reformas por meio desse discurso.

Flores (2014), em revisão recente sobre Discursos do profissionalismo docente, descreve diferentes abordagens acerca desse conceito, que variam desde uma perspectiva estrutural-funcionalista até o profissionalismo gerencialista e o democrático. Baseando-se em Sachs (2003) e Flores (2014), afirma que o profissionalismo gerencialista surge relacionado com a mudança organizacional, com imperativos ligados a uma maior prestação de contas e com questões de eficiência e de eficácia. Nesse contexto, o profissional responde a metas pré-especificadas externamente, gere bem um conjunto de alunos e documenta os seus resultados para efeitos de prestação pública de contas. Assim, o bom profissional é aquele que responde aos critérios de sucesso preconizados, ou seja, trabalha de forma eficaz e eficiente para ir ao encontro dos critérios padronizados definidos para alunos, professores e escolas.

Contrariamente, para Flores (2014), o profissionalismo democrático procura desmistificar o trabalho profissional e construir alianças entre professores e outros agentes, enfatizando a ação colaborativa e cooperativa. O professor surge com responsabilidades mais amplas, para além da sala de aula, incluindo o contributo para a escola, para o sistema educativo, a comunidade e os alunos, bem como responsabilidades coletivas enquanto profissão, com vista à construção de uma sociedade mais justa.

Do nosso ponto de vista, tal visão de profissionalismo democrático não difere em muito do que foi definido como profissionalismo gerencialista, salvo pelas intenções. Em realidade, o conceito de profissionalismo, ou de "novo profissionalismo", na atualidade surge no contexto da NGP evocando valores de inovação, criatividade, flexibilidade, iniciativa e responsabilidade congruentes aos novos modelos de organização do trabalho no capitalismo, que apelam frequentemente para a colaboração e a colegialidade sem discutir os fins últimos da produção.

A retórica sobre o novo profissionalismo argumenta que há uma mudança emergente nos valores e práticas dos professores. O conceito de "novo profissionalismo" tem sido controverso em diferentes grupos de ocupação com uma longa história. Especialmente no terreno sociológico é tema de muitos debates acadêmicos, prevalencendo basicamente duas versões do profissionalismo docente que se opõem e que são retratadas como "profissionalismo antigo" e "novo profissionalismo". Essas duas abordagens não são completamente opostas entre si.

De acordo com Sachs (2003), quem primeiro desenvolveu esta classificação, essas duas abordagens se diferenciam: profissionalismo antigo está preocupado com: a) filiação exclusiva a uma organização/instituição; b) práticas conservadoras; c) interesse próprio; d) regulação externa; e) lenta mudança; e f) reativa. As características do novo profissionalismo (transformador) são: a) filiação inclusiva; b) código de ética de prática pública; c) colaborativa e colegiada; d) orientação ativista; e) flexível e progressista; f) mudança responsiva; g) autorregulação; h) política ativa; i) orientada para a investigação; j) construção do conhecimento. É notória a forma depreciativa com que o autor define o profissionalismo tradicional em contraposição a uma apologia dos valores supostamente contidos no novo profissionalismo. 
Essas abordagens reivindicam uma nova compreensão do profissionalismo docente que ofereça espaço profissional e condições para os professores que têm responsabilidade sobre suas práticas, como se no estatuto anterior os professores agissem de forma irresponsável. Sachs (2003) chama essa transição do antigo para o novo profissionalismo como o entendimento de uma ação transformadora. A abordagem de Sachs (2003) de profissionalismo docente pode ser interpretada como uma tentativa de revitalizar o conceito em um ambiente de trabalho que muda rapidamente, mas o faz embriagado pelo sentido de inovação, de forma acrítica, descontextualizada do ponto de vista da estrutura econômica. Ele considera a questão do profissionalismo do professor como estratégia social e política para promover o status da profissão docente. Sua intenção nessa abordagem é oferecer uma alternativa contemporânea quando comparada à abordagem tradicional do profissionalismo docente. Entretanto, dimensões importantes do problema deixaram de ser contempladas.

De acordo com Grek (2016), as análises do campo dos estudos de ciência e tecnologia têm explorado o novo papel regulador dos atores do conhecimento transnacionais, que devem possuir tanto a base de conhecimento quanto a rede de especialistas necessária para produzir evidências científicas para a formulação de políticas. Segundo Grek (2016, p. 722), em

[...] uma interessante análise do Banco Mundial, na produção de políticas de combate à pobreza global, Clair (2006) mostrou a natureza de negociação dos dados 'objetivos' oferecidos por essas instituições: 'definições e avaliações não são relatos de fatos, mas sim 'substitutos de fatos', partes bem estruturadas de um todo mal estruturado e complexo'.

A difusão de determinados valores por meio da "fabricação de verdades" que se utilizam de instrumentos como a avaliação externa (PISA) e de grandes bases de dados (TALIS), como mecanismos de produção de evidências sobre a situação educativa no mundo buscando influenciar os rumos das políticas nacionais são expressões de um modo de regulação transnacional que se impõe na atualidade (CARVALHO, 2016). Do ponto de vista da teoria crítica é necessário desenvolver outras bases e instrumentos de investigação em perspectiva comparada que possam contrapor-se a essas evidências, a desvelar os objetivos dessa governação por números, por exemplo, contrapondo à difusão de criterios de qualidade que privilegiam determinadas dimensões do conhecimento e enfoques da profissão que favoreçem um modelo econômico específico.

O discurso construído e difundido pelas reformas educativas nos países dessa região, articulado a um processo global, em escala internacional, tem naturalizado a eficiência capitalista no âmbito do Estado como fim em si mesma, obscurescendo importantes noções de direito, conquistadas a duras penas ao longo do século XX, que deveriam reger as relações entre Estado e sociedade. Esse discurso que atinge a educação como uma política pública, mas que está presente em todos os campos da ação estatal, tem desenvolvido mecanismos de manipulação das identidades docentes nos moldes apontados por Lawn (2001), com uma finalidade ideológica. A retórica em torno da produção de "bons professores" como profissionais reflexivos, responsáveis, inovadores, criativos, apela para um professor "super-herói" que possa garantir a aprendizagem dos alunos independentemente das condições oferecidas.

As políticas centradas na preparação de professores para responderem às necessidades de aprendizagem visam justamente à modelação desses profissionais, no sentido demonstrado por Pettersson e Molstad (2016), para cumprirem os objetivos do PISA. Os professores acabam tendo suas identidades definidas pelo que se espera dele e de suas funções, já que são considerados elementos estratégicos para o alcance da aprendizagem para a redução das desigualdades. Esses processos de avaliação, responsáveis pela produção de evidências e, ao mesmo tempo, por moldarem professores e suas funções, ou seja, promoverem uma reestruturação em elementos-chave da profissão, são processos de inclusão e exclusão social, já que tratam de selecionar os que são eficientes e os que não são e demonstrá-lo por meio da prestação de contas, das políticas de accountability.

Essas políticas focadas nos resultados acadêmicos promovem um ambiente interno altamente competitivo, já que as performances passam a ser 
constantemente avaliadas e seus resultados demonstrados. Os professores sentem que sua posição profissional é constantemente desrespeitada em uma cultura frequente de "auditoria" (ANDERSON, 2017).

Essas políticas podem produzir novas segmentações no coração da profissão docente ou contribuir para as já existentes, dificultando a conformação de coletivos de trabalho: aumentam os contrastes entre professores efetivos e contratados com a adoção cada vez mais ampla da flexibilidade do mercado, referenciada como um valor positivo, dicotomias que são observadas nos discursos que apelam para a condição individual em detrimento do grupo profissional; professores resistentes à mudança e professores "aprendentes"; responsabilidade individual; relações que revelam contrastes entre diferentes regiões, ou mesmo redes de ensino etc.

Esse discurso, que se centra na responsabilidade dos docentes de melhorar o rendimento dos alunos nas provas em um contexto de grande desigualdade social, tem contribuído para a perda de confiança nos docentes como profissionais e para uma depreciação de sua carreira e de sua profissionalização, ainda mais em um contexto de débil reconhecimento de seu papel profissional.

\section{REFERÊNCIAS}

ANDERSON, G.; HERR, K. New public management and the new professionalism in education: framing the issue. Education Policy Analysis Archives, v. 23, n. 84, p. 1-9, 2015.

ANDERSON, G. Privatizando subjetividades: como a nova gestão pública (NGP) está criando o "novo" profissional da educação. RBPAE, v. 33, n. 3, p. 593-626, set./dez. 2017.

BALL, S. J.; YOUDELL, D. Privatización encubierta en la educación pública. Informe preliminar. Bruselas, 2007.

BIRGIN, A. La docencia como trabajo: la construcción de nuevas pautas de inclusión y exclusión. In: GENTIL, P.; FRIGOTTO, G. (Comp.). La ciudadanía negada: políticas de exclusión en la educación y el trabajo. Buenos Aires: CLASCO, 2000.

BRUNS, B.; LUQUE, J. Professores excelentes - como melhorar a aprendizagem dos estudantes na América Latina e no Caribe. Washington, D.C.: Banco Mundial, 2014.

CAMARGO, R. C.; JACOMINI, M. A. Carreira e salário do pessoal docente da Educação Básica: algumas demarcações legais. Revista Educação em Foco, ano. 14, n. 17, p. 129-167, 2011.

CARVALHO, L. Intensificação e sofisticação dos processos da regulação transnacional em educação: o caso do Programa Internacional de Avaliação de Estudantes. Educação \& Sociedade, Campinas, SP, v. 37, n. 136, p. 669683, 2016.

COMISIÓN ECONÓMICA PARA AMÉRICA LATINA Y EL CARIBE (Cepal); ORGANIZACIÓN DE LAS NACIONES UNIDAS PARA LA EDUCACIÓN, LA CIENCIA Y LA CULTURA (Unesco). Invertir mejor para invertir más. Financiamiento y gestión de la educación en América Latina y el Caribe. Santiago, 2005. (Serie Seminarios y Conferencias, $\mathrm{n}^{\circ} 43$ ).

CUENCA, R. Las carreras docentes em América Latina. La acción meritocrática para el desarollo profesional. Santiago: OREALC/Unesco, 2015.

DEMAZIÈRE, D.; ROQUET, P.; WITTORSKI, R. La professionnalisation mise en objet. Paris: L'Harmattan, 2012.

DEMAZIERE, D.; LESSARD, C.; MORRISSETE, J. Les effets de la Nouvelle Gestion Publique sur le travail des professionnels: transpositions, variations, ambivalences. Éducation \& Sociétés, v. 2, n. 32, p. 5-20, 2013.

DEMIRKASIMOGLU, N. Defining "Teacher Professionalism” from different perspectives. Procedia - Social and Behavioral Sciences, v. 9, p. 2047-2051, 2010.

DUARTE, A. W. B. Por que ser professor? Uma análise da carreira docente na educação básica no Brasil. 2013. 164 f. Dissertação (Mestrado em Educação) - Programa de Pós-Graduação em Educação, Conhecimento e Inclusão Social da Faculdade de Educação da Universidade Federal de Minas Gerais (UFMG), Belo Horizonte, 2013.

FELDFEBER, M.; IMEN, P. A formação continuada dos docentes: os imperativos da profissionalização em con- 
textos de reforma educativa. In: FERREIRA, N. S. C. (Org.). Formação continuada e gestão da educação. 3. ed. São Paulo: Cortez, 2007. p. 165-185.

FLORES, M. A. Discursos do profissionalismo docente paradoxos e alternativas conceptuais. Revista Brasileira de Educação, v. 19, n. 59, p. 851-869, out./dez. 2014.

GIDDENS, A. Modernidade e identidade. Rio de Janeiro: Zahar, 2002.

GREK, S. Atores do conhecimento e a construção de novos cenários de governança: o caso da Direção-Geral de Educação e Cultura da Comissão Europeia. Educação \& Sociedade, Campinas, SP, v. 37, n. 136, p. 707-726, 2016.

GRUENING, G. Origin and theoretical basis of New Public Management. International Public Management Journal, n. 4, p. 1-25, 2001.

LAWN, M. Os professores e a fabricação de identidades. Currículo sem Fronteiras, v. 1, n. 2, p. 117-130, jul./ dez. 2001.

MALET, R. Former, réformer, transformer la main-d'œuvre enseignante? Politiques comparées et expériences croisées anglo-américaines. Education et Sociétés, v. 1, n. 23, p. 91-122, 2009.

OLIVEIRA, D. A. Educação e planejamento: a escola como núcleo da gestão. In: crática da educação: desafios contemporâneos. 2. ed. Petrópolis, RJ: Vozes, 1997. p. 174-195.

(Org.). Gestão demo-

Educação básica: gestão do trabalho e da pobreza. Petrópolis, RJ: Vozes, 2000.

Mudanças na organização e na gestão do trabalho na escola. In: OLIVEIRA, D. A.; ROSAR, M. F. F. (Org.). Política e gestão da educação. Belo Horizonte: Autêntica, 2002. p. 125-144.

A reestruturação do trabalho docente: precarização e flexibilização. Educação \& Sociedade, Campinas, $\overline{\text { SP, v. } 25, ~ n . ~ 89, ~ p . ~ 1127-1144, ~} 2004$.

OLIVEIRA, D. A.; DUARTE, A. W.; CLEMENTINO, A. M. A nova gestão pública no contexto escolar e os dilemas dos(as) diretores(as). RBPAE, v. 33, n. 3, p. 707-726, set./dez. 2017.

ORGANIZAÇÃO INTERNACIONAL DO TRABALHO (OIT); ORGANIZAÇÃO DAS NAÇÕES UNIDAS PARA A EDUCACIÓN, A CIENCIA E A CULTURA (Unesco). Recomendação da Organização Internacional do Trabalho (OIT) e Unesco de 1966. Paris, 1966.

ORGANIZATION FOR ECONOMIC CO-OPERATION AND DEVELOPMENT (OECD). Le rôle crucial des enseignants: attirer, former et retenir des enseignants de qualité. Aperçu. Paris, 2005.

PETTERSSON, D.; MOLSTAD, C. E. Professores do Pisa: a esperança e a realização da educação. Educação \& Sociedade, Campinas, SP, v. 37, n. 136, p. 629-645, jul./set. 2016.

POPKEWITZ, T. El Estado y la administración de la libertad a finales del siglo XX: descentralización y distinciones Estado/sociedad civil. In: PEREYRA, M. Et al. Globalización y descentralización de los sistemas educativos: fundamentos para un nuevo programa de la educación comparada. Barcelona: Ediciones Pomares-Corredor S/A, 1996. p. 119-168.

POPKEWITZ, T.; LINDBLAD, S. Estatísticas educacionais como um sistema de razão: relações entre governo da educação e inclusão e exclusão sociais. Educação \& Sociedade, Campinas, SP, v. 22, n. 75, p. 111-148, ago. 2001.

RODRIGUES, M. L. Sociologia das profissões. Oeiras, PT: Celta, 2002.

SACHS, J. The activist teaching profession. Buckigham: Open University Press, 2003.

SALAMA, P.; VALIER. Pobrezas e desigualdades no terceiro mundo. São Paulo: Nobel, 1997.

TENTI-FANFANI, E. T. La condición docente. Buenos Aires: Siglo Veintiuno, 2005.

TERIGI F. Desarrollo profesional continuo y carrera docente en América Latina. Santiago de Chile: PREAL, 2010. (Série Documentos, $\mathrm{n}^{\circ} 50$ ).

TIRAMONTI, G. Sindicalismo docente y reforma educativa en la América Latina de los 90. Santiago de Chile: PREAL,2001. (Série Documentos, $\mathrm{n}^{\circ}$ 19).

VAILLANT, D. Iniciativas mundiales para mejorar la formación de profesores. Revista Brasileira de Estudos Pedagógicos, Brasília, DF, v. 91, n. 229, p. 543-561, set./dez 2010. 
Formación inicial del profesorado en América Latina: dilemas centrales y perspectivas. Revista Española de Educación Comparada, n. 22, p. 185-206, 2013.

VERGER, A.; NORMAND, R. Nueva gestión pública y educación: elementos teóricos y conceptuales para el estudio de un modelo de reforma educativa global. Educação \& Sociedade, Campinas, SP, v. 36, n. 132, p. 599622, jul./set. 2015.

Recebido em: 01/07/2018

Aprovado em: 10/08/2018 